\title{
Clinical outcomes of late decompression surgery following cervical spinal cord injury with pre-existing cord compression
}

\author{
Tsunehiko Konomi $\mathbb{C}^{1} \cdot$ Akimasa Yasuda $^{1} \cdot$ Kanehiro Fujiyoshi $^{1} \cdot$ Junichi Yamane $^{1} \cdot$ Shinjiro Kaneko $^{1} \cdot$ \\ Takatsugu Komiyama $^{1}$. Masakazu Takemitsu ${ }^{1}$ Y Yoshiyuki Yato ${ }^{1} \cdot$ Osahiko Tsuji $^{2} \cdot$ Morio Matsumoto $^{2}$. \\ Masaya Nakamura ${ }^{2}$ Takashi Asazuma ${ }^{1}$
}

Received: 6 June 2017 / Revised: 9 September 2017 / Accepted: 14 September 2017 / Published online: 19 December 2017

(c) International Spinal Cord Society 2018

\begin{abstract}
Study design Retrospective cohort study.

Objectives The purpose of the current study was to examine the effectiveness of late decompression surgery for traumatic cervical spinal cord injury (CSCI) with pre-existing cord compression.

Setting Murayama Medical Center, National Hospital Organization, Tokyo, Japan.

Methods In total 78 patients with traumatic CSCI without bone injury hospitalized in 2012-2015 in our institute for rehabilitation after initial emergency care were divided into four groups according to the compression rate (CR) of the injured level and whether or not decompression surgery was performed. Neurological status was evaluated by American Spinal Injury Association impairment scale (AIS), Barthel index, and Spinal Cord Independence Measure (SCIM).

Results In the severe compression group (CR $\geq 40 \%$ ), $>2$ grade improvement in the AIS was observed in $30 \%$ of patients with surgical treatment, although it was not observed in any patient without surgery. The SCIM improvement rate at discharge was $60 \%$ in the surgical treatment group and $20 \%$ in the non-surgical treatment group. In the minor compression group $(\mathrm{CR}<40 \%),>2$ grade improvement in the AIS was observed in $18 \%$ of patients with surgical treatment and in $11 \%$ without surgery. The SCIM improvement rate at discharge was 52\% in the surgical treatment group and $43 \%$ in the nonsurgical treatment group.

Conclusions These results indicate that surgical treatment has an advantage for patients following traumatic CSCI with severe cord compression. In contrast, surgical efficacy is not proved for CSCI patients without severe cord compression.
\end{abstract}

\section{Introduction}

Functional prognosis following traumatic spinal cord injury depends on primary damage, such as the dynamic mechanistic force and static pre-existing or concurrent cord compression, and secondary damage, such as edema, ischemia, and inflammation, which lead to demyelination of axons, apoptosis of neural cells, and glial scar formation in

Tsunehiko Konomi

konomitsunehiko@gmail.com

1 Department of Orthopaedic Surgery, Murayama Medical Center, National Hospital Organization, 2-37-1 Gakuen,

Musashimurayama, Tokyo 208-0011, Japan

2 Department of Orthopaedic Surgery, Keio University School of Medicine, 35 Shinanomachi, Shinjuku, Tokyo 160-8582, Japan the spinal cord [1-7]. Some patients with incomplete spinal cord injury recover function to a certain extent, although others do not recover sufficiently [8]. Of the factors affecting traumatic cervical spinal cord injury (CSCI) without bone injury, pre-existing cord compression is an important issue to consider. In general, pre-existing canal stenosis does not affect severity or prognosis after CSCI [3, 5,9-12]. In contrast, greater than $50-60 \%$ canal stenosis is a key threshold as to whether deterioration of motor function occurs in patients with cervical spondylotic myelopathy and ossification of the posterior longitudinal ligament (OPLL) of the cervical spine $[13,14]$. Furthermore, this phenomenon was demonstrated using an in vivo experimental rodent model [15], and a biomechanical 3D finite element spinal cord model concluded that greater than $40 \%$ compression of the anteroposterior diameter might contribute to the occurrence of myelopathy [16]. However, the effectiveness of decompression surgery for pre-existing cord 
Table 1 Patient demographics: neurological level of injury, MRI characteristics and Surgical characteristics

\begin{tabular}{|c|c|c|c|c|c|c|}
\hline & \multicolumn{3}{|c|}{ Compression rate $\geq 40 \%$} & \multicolumn{3}{|c|}{ Compression rate $<40 \%$} \\
\hline & $\begin{array}{l}\text { Surgery }(+) \\
n=20\end{array}$ & $\begin{array}{l}\text { Surgery }(-) \\
n=12\end{array}$ & $P$-value & $\begin{array}{l}\text { Surgery }(+) \\
n=11\end{array}$ & $\begin{array}{l}\text { Surgery }(-) \\
n=35\end{array}$ & $P$-value \\
\hline \multirow[t]{4}{*}{ Neurological level of injury (no. of Pts. (\%)) } & C3 & $0(0)$ & & $0(0)$ & $0(0)$ & $1(3)$ \\
\hline & $\mathrm{C} 4$ & $4(20)$ & & $4(33)$ & $4(36)$ & $10(29)$ \\
\hline & $\mathrm{C} 5$ & $15(75)$ & & $5(42)$ & $6(55)$ & $17(49)$ \\
\hline & C6 & $1(5)$ & & $3(25)$ & $1(9)$ & $7(20)$ \\
\hline \multicolumn{7}{|l|}{ MRI Characteristics } \\
\hline Compression rate (\%; mean (SD)) & $53(10)$ & $52(7)$ & 0.975 & $26(7)$ & $19(11)$ & 0.150 \\
\hline Pre-vertebral hyper intensity (no. of Pts. (\%)) & $12(60)$ & $5(42)$ & 0.440 & $8(73)$ & $24(69)$ & 0.588 \\
\hline Intervertebral disc herniation (no. of Pts. (\%)) & $6(30)$ & $1(8)$ & 0.161 & $3(27)$ & $3(8)$ & 0.113 \\
\hline \multicolumn{7}{|l|}{ Surgical Characteristics } \\
\hline Surgical timing (day after injury; mean (SD)) & $27(26)$ & - & & $40(43)$ & - & 0.915 \\
\hline Decompression only (no. of Pts. (\%)) & $15(75)$ & - & & $9(82)$ & - & 0.677 \\
\hline Decompression + Stabilization (no. of Pts. $(\%)$ ) & $5(25)$ & - & & $2(18)$ & - & 0.677 \\
\hline
\end{tabular}

compression remains controversial. The purpose of the present study was to examine the effectiveness of late decompression surgery for pre-existing cord compression following traumatic CSCI without bone injury.

\section{Methods}

This was a retrospective cohort study. A total of 83 consecutive patients with CSCI without bone injury, who were admitted to our institute for rehabilitation after initial emergency care (it included surgical treatment) from April 2012 to September 2015, were potentially eligible for inclusion in this study. Seventy-eight patients who did not meet the following exclusion criteria were selected retrospectively: (1) patients who underwent cervical surgery before $24 \mathrm{~h}$ or after 90 days post-injury; (2) duration of hospitalization was less than 90 days, and (3) patients with disturbed consciousness such as brain injury or a severe mental disorder that might influence their rehabilitation training. Of 83 patients with CSCI, 5 patients were excluded and the reasons were surgery within $24 \mathrm{~h}$ post-injury (1 case), after 90 days post-injury ( 3 cases) and severe mental disorder due to dementia ( 1 case).

The patients were divided into four groups according to the compression rate (CR) of the injured spinal cord (severe or minor compression), and whether or not decompression surgery was undertaken. The indication criteria and/or method of surgical treatment were different according to the clinician who initially managed the CSCI patient. Greater than or equal to $40 \% \mathrm{CR}$ was defined as severe compression, and $<40 \%$ was defined as minor compression. The rate of spinal cord compression was measured using the sagittal view of magnetic resonance imaging (MRI) at the time of injury. A high signal intensity area in the cervical cord on T2-weighted MR images was determined as the injured level. The rate of spinal cord compression was measured by T1-weighted MR sagittal view images and calculated using the following formula [9]: CR $(\%)=$ (diameter of cord at the injured level-diameter of the noncompression level)/diameter at the injured level $\times 100$. In cases with OPLL, CR was calculated not in the most restricted area but in the area where a signal intensity changing was seen. We also evaluated existence of prevertebral hyper intensity area and intervertebral disc herniation on T2-weighted MR sagittal view for assessment of soft tissue damage [4].

Neurological status was evaluated using the American Spinal Injury Association impairment scale (AIS) grade at the time of injury and discharge from our institute [17]. Functional recovery was evaluated by the modified Barthel index (BI) [18] and spinal cord independence measure (SCIM) [20-21] at transfer and admission to our institute, at 3 months after treatment, and at discharge. Functional recovery was evaluated by the following formula [10, 22]: Improvement rate $(\%)=$ (score at 3 months or dischargescore at admission $) /(100-$ score at admission $) \times 100$. Statistical analyses were performed using one-way analysis of variance and post-hoc Tukey-Kramer test for comparison of longitudinal changes in the BI and SCIM of each group. $t$-Tests were applied to compare the average of continuous variables (age, duration of hospital stay, days of evaluation, 
Table 2 Functional improvement outcomes in the SCIM and BI at 3 months and at the time of discharge from our center

\begin{tabular}{lllllll}
\hline & & \multicolumn{2}{l}{ Compression rate $\geq 40 \%$} & & \multicolumn{2}{l}{ Compression rate $<40 \%$} \\
& & Surgery $(+)$ & Surgery $(-)$ & & Surgery (+) & Surgery $(-)$ \\
\hline Barthel index improvement rate & at 3 months & $39(26)$ & $27(32)$ & & $43(37)$ & $37(31)^{*}$ \\
$(\% ;$ mean (SD)) & at discharge & $65(31)^{*}$ & $36(40)$ & & $58(31)^{*}$ & $52(38)^{*}$ \\
Spinal cord independence measure & at 3 months & $39(23)$ & $14(18)$ & & $39(30)$ & $29(27)$ \\
improvement rate (\%; mean (SD)) & at discharge & $60(27)^{*}$ & $20(28)$ & & $52(29)$ & $43(33)^{*}$ \\
\hline
\end{tabular}

$* P<0.05$

\begin{tabular}{|c|c|c|c|c|c|}
\hline \multirow[t]{2}{*}{ a } & \multicolumn{5}{|c|}{ On Discharge } \\
\hline & A & B & $\mathrm{C}$ & D & $\mathrm{E}$ \\
\hline & & & & & \\
\hline & & & 1 & 3 & \\
\hline & & & 4 & 9 & 3 \\
\hline & & & & & \\
\hline & 20 Pts. & & $\begin{array}{l}\text { ssio } \\
\text { argic }\end{array}$ & $\begin{array}{l}\geq 4 \\
\mathrm{eatm}\end{array}$ & \\
\hline
\end{tabular}

1 grade AIS improvement

more than 2 grade AIS improvement

\begin{tabular}{|c|c|c|c|c|}
\hline \multicolumn{5}{|c|}{ On Discharge } \\
\hline A & B & $\mathrm{C}$ & $\mathrm{D}$ & $\mathrm{E}$ \\
\hline & & & 1 & \\
\hline & & 1 & & \\
\hline & & 1 & 6 & 1 \\
\hline & & & & 1 \\
\hline
\end{tabular}

\section{b On Discharge}

\begin{tabular}{cccccc}
\hline & A & B & C & D & E \\
\hline A & 1 & & & & \\
\hline B & & 1 & 1 & & 1 \\
C & & & 4 & 3 & 1 \\
\hline D & & & 1 \\
\hline Total 12 Pts. & $\begin{array}{r}\text { Compression Rate } \geq 40 \% \text { without } \\
\text { Surgical Treatment }\end{array}$ \\
\hline
\end{tabular}

\begin{tabular}{ccccccc}
\hline d & On Discharge & & & & \\
\hline A & B & C & D & E
\end{tabular}

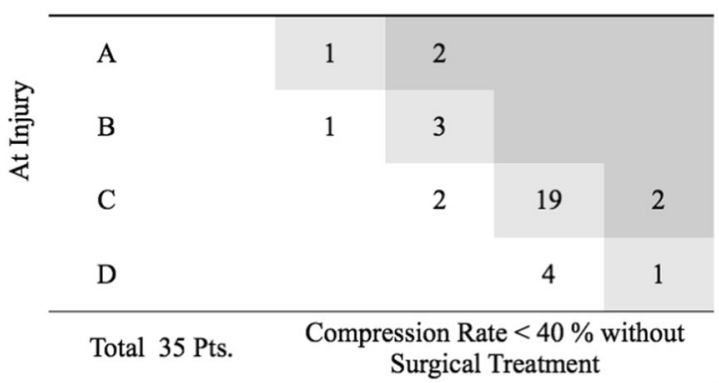

Fig. 1 Neurological outcomes of CSCI in AIS grade between injury and discharge from our center. a: CR $\geq 40 \%$ with surgical treatment, b: CR $\geq$ $40 \%$ without surgical treatment, $\mathbf{c}$ : $\mathrm{CR}<40 \%$ with surgical treatment, $\mathbf{d}$ : $\mathrm{CR}<40 \%$ without surgical treatment

MRI findings and surgical characteristics). Missing data for the BI and SCIM were replaced by linear interpolation in cases where the missing scores fell between two valid scores. Categorical data of AIS grade were analyzed by Fisher's exact and chi-squared tests. Statistical analyses were performed using Prism 5.0 (GraphPad Software). In all statistical analyses, significance was accepted at a value of $P<0.05$.

\section{Results}

The 78 patients consisted of 66 males and 12 females, and the mean age was 67 years (range 35-91). The mean timing of initial evaluation of AIS and final evaluation were 0.2 days (range 0-4) and 243 days (range 97-594) postinjury, respectively. The mean timing of transfer to our center and the mean duration of hospital stay of our center were 46 days post-injury (range 1-132) and 190 days (range 90-530). As shown in Table 1, most of neurological level of 
injury were C4 and C5. Pre-vertebral hyper intensity and intervertebral disc herniation were identified in 50 patients (63\%) and 14 patients (18\%), respectively. Of the 32 patients who were categorized in the severe compression group with a mean CR of 52\%, 20 (63\%) underwent surgery at a mean of 27 days after injury. Of the 46 patients who were categorized in the minor compression group with a mean CR of $21 \%, 11(24 \%)$ underwent surgery at a mean of 40 days after injury (Table 1 ).

As shown in Table 2, in the severe compression group, the BI and SCIM improvement rates demonstrated significant improvement at the time of discharge only in the surgical treatment group. In contrast, in the minor compression group, there were statistically significant improvements of both the BI and SCIM at the time of discharge in the non-surgical treatment group, and of the BI in the surgical treatment group.

As shown in Fig. 1, in the severe compression group, of the 20 patients who underwent surgery, 6 (30\%) improved by more than 2 grades and $16(80 \%)$ improved at least 1 grade in the AIS between injury and discharge. Of the 12 patients in whom surgery was not performed, no one $(0 \%)$ improved by 2 grades and $5(42 \%)$ improved at least 1 grade in the AIS ( $\geq 2$ grade AIS improvement (surgical treatment vs. non-surgical treatment): odds ratio $(\mathrm{OR})=$ 11.2, 95\% confidence interval (CI): $0.6,219.5, P=0.061$. Adding 0.5 to each value for calculating only this $\mathrm{OR}, \geq 1$ grade AIS improvement: $\mathrm{OR}=5.6,95 \% \mathrm{CI}: 1.2,27.4, P=$ $0.053, \geq 1$ grade AIS improvement in AIS $\mathrm{C}$ at injury: $\mathrm{OR}=$ 4.6, 95\% CI: $0.5,26.0, P=0.0182$ ).

In the minor compression group, of the 11 patients who underwent surgery, 2 (18\%) improved by $>2$ grades and 10 (91\%) improved at least 1 grade in the AIS between injury and discharge. Of the 35 patients without surgical treatment, $4(11 \%)$ improved by $>2$ grades and $28(80 \%)$ improved at least 1 grade in the AIS ( $\geq 2$ grade AIS improvement: OR = 1.72, 95\% CI: $0.27,10.99, P=0.619, \geq 1$ grade AIS improvement: $\mathrm{OR}=2.50,95 \%$ CI: $0.27,22.9, P=0.658$, $\geq 1$ grade AIS improvement in AIS C at injury: $\mathrm{OR}=0.7$, 95\% CI: $0.1,8.5, P=1.00$ ).

\section{Discussion}

In this study, we observed two major findings. First, a significant recovery of daily activity and motor function was obtained by late surgical decompression in the severe compression group. Second, CSCI patients with minor compression recovered sufficiently without surgical treatment.

Kawano et al. [9] demonstrated that there was no difference between surgical treatment and conservative treatment in CSCI patients with a cord CR $>20 \%$ in their multi- center prospective study. In contrast, the surgical outcomes in patients with cervical spondylotic myelopathy or OPLL demonstrated that postoperative recovery was poorer in those with severe cord compression [23-25], and the duration between the onset of the initial symptoms and surgery was correlated with negative clinical results in patients with OPLL of the cervical spine [26]. Furthermore, neurological recovery was seen with decompression surgery in patients with CSCI associated with OPLL who had gait disturbance before injury [27]. Other authors have advocated the efficacy of decompression surgery for CSCI [28-31]. In the present study, in the severe cord compression group, although the non-surgical treatment patients did not recover significantly in the BI, SCIM, and AIS, the surgical treatment patients recovered significantly. In the minor compression group, in contrast, sufficient functional improvements were acquired even by conservative treatment. These results indicate that neurological recovery tends to be interrupted by severe cord compression, and decompression surgery can be effective when the $\mathrm{CR}$ is severe or above a threshold level.

On the contrary, surgical treatment has not contributed to prognosis after CSCI with minor cord compression. Kawano et al. [9] reported that a CR of $\sim 20 \%$ was the threshold for an indication for decompression surgery. In comparison with our study, a CR of $20 \%$ (the average CR of the former study was $28.7 \%$ ) would be classified as minor compression, and the lack of an obvious advantage of surgical treatment in their study is consistent with our findings.

The timing of surgical intervention in the present study was limited to the late phase, which was defined as greater than 1 day $(24 \mathrm{~h})$ and less than 90 days after injury. The reason that we excluded operation after 90 days post-injury is the neurological recovery after injury becomes plateau between 3 and 6 months after injury [9]. So, if a surgical treatment would be performed after 90 days post-injury, we forecast that the surgical effectiveness and neurological recovery might be limited. The effectiveness of early vs. late decompression surgery for CSCI on neurological recovery is controversial [32-36]. Newton et al. [37] reported that the time from injury to reduction was important for reperfusion of the spinal cord in CSCI patients with a major dislocation. Guest et al. [38] reported that a greater improvement was observed in CSCI patients with acute disc herniation or fracture/dislocation who underwent surgical treatment before $24 \mathrm{~h}$ than in those who underwent surgery in the later phase. In contrast, there was no significant difference in surgical efficacy between early and late surgery for CSCI patients with spinal stenosis. Furthermore, preexisting canal stenosis is not always an impediment due to the potential restructuring of spinal cord blood flow, which was proved in an in vivo experimental animal study [2]. In the present study, although the timing of surgical treatment 
was limited after $24 \mathrm{~h}$, a remarkable improvement was obtained in CSCI patients with severe cord compression. It indicated that pre-existing cord compression might have a positive influence on the spinal cord in terms of compensational blood flow, and concurrent stenosis might not exist paradoxically.

The limitations of this study were retrospective study, the small number of patients assessed, and the indication criteria and/or method of surgical treatment were different according to the clinician who initially managed the CSCI patient. So, assessments of soft tissue damage such as ligamentous injury and existence of instability were not considered uniformly. Furthermore, ASIA motor score was not recorded in all the cases because of diversity of clinician concerning before transfer to our center. In addition, certain factors, such as injured level and degree of paralysis, were not matched between the groups. Although the number of patients was small and the methods of management were different from a statistical standpoint, our findings suggest an efficacy of late surgical treatment for CSCI patients with severe cord compression. Concerning the difference in the degree and level of injury, we did not use average scores to evaluate paralysis, but instead used the ratio of improvement in the SCIM in each patient, which enabled us to assess neurological recovery more sensitively and uniformly from the viewpoint of daily performance. Furthermore, we set the duration of hospital stay was limited to over 90 days. It enable patients to receive adequate rehabilitation training for achievement of abilities of daily life and we could assess whether the neurological recovery became plateau.

In this study, cord CR did not reflect the severity of injury, which is consistent with former studies $[10,11]$. However, it is also known that cord compression itself is a risk factor for traumatic CSCI [30, 39, 40]. From the viewpoint of the prevention of further SCI and subsequent neurological deterioration, decompression surgery for CSCI with severe cord compression would provide a potential advantage over conservative management. A randomized prospective trial designed to evaluate the efficacy of surgical treatment for CSCI from multiple viewpoints such as cord compression, traumatic force, soft-tissue damage, spasticity and instability is necessary for further study.

\section{Conclusions}

In conclusion, this study indicated that decompression surgery could be an option for patients with severe cord compression even in the late phase. In contrast, because good functional recovery was obtained by conservative treatment, decompression surgery is not always necessary for CSCI patients without severe cord compression. In consideration of the high risk of complications after CSCI, adequate caution should be taken according to the overall condition of individual patients.

\section{Data archiving}

There were no data to deposit.

\section{Compliance with ethical standards}

Conflict of interest The authors declare that they have no competing interests.

\section{References}

1. McDonald JW, Sadowsky C. Spinal-cord injury. Lancet. 2002;359:417-25.

2. Kubota K, Saiwai H, Kumamaru H, Kobayakawa K, Maeda T, Matsumoto Y, et al. Neurological recovery is impaired by concurrent but not by asymptomatic pre-existing spinal cord compression after traumatic spinal cord injury. Spine. 2012;37:1448-55.

3. Kawano O, Maeda T, Mori E, Yugue I, Takao T, Sakai H, et al. Influence of spinal cord compression and traumatic force on the severity of cervical spinal cord injury associated with ossification of the posterior longitudinal ligament. Spine (Phila $\mathrm{Pa}$ 1976) 2014;39:1108-12.

4. Iwanami A, Yamane J, Katoh H, Nakamura M, Momoshima S, Ishii $\mathrm{H}$, et al. Establishment of graded spinal cord injury model in a nonhuman primate: the common marmoset. J Neurosci Res. 2005;80:172-81.

5. Maeda T, Ueta T, Mori E, Yugue I, Kawano O, Takao T, et al. Soft-tissue damage and segmental instability in adult patients with cervical spinal cord injury without major bone injury. Spine. 2012;37:E1560-6.

6. Okano H, Kaneko S, Okada S, Iwanami A, Nakamura M, Toyama Y. Regeneration-based therapies for spinal cord injuries. Neurochem Int. 2007;51:68-73.

7. Thuret S, Moon LD, Gage FH. Therapeutic interventions after spinal cord injury. Nat Rev Neurosci. 2006;7:628-43.

8. Marino RJ, Ditunno JF Jr, Donovan WH, Maynard F Jr. Neurologic recovery after traumatic spinal cord injury: data from the model spinal cord injury systems. Arch Phys Med Rehabil. 1999;80:1391-6.

9. Kawano O, Ueta T, Shiba K, Iwamoto Y. Outcome of decompression surgery for cervical spinal cord injury without bone and disc injury in patients with spinal cord compression: a multicenter prospective study. Spinal Cord. 2010;48:548-53.

10. Okada S, Maeda T, Ohkawa Y, Harimaya K, Saiwai H, Kumamaru H, et al. Does ossification of the posterior longitudinal ligament affect the neurological outcome after traumatic cervical cord injury?. Spine. 2009;34:1148-52

11. Takao T, Okada S, Morishita Y, Maeda T, Kubota K, Ideta R, et al. Clinical influence of cervical spinal canal stenosis on neurological outcome after traumatic cervical spinal cord injury without major fracture or dislocation. Asian Spine J. 2016;10:536-42.

12. Ishida Y, Tominaga T. Predictors of neurologic recovery in acute central cervical cord injury with only upper extremity impairment. Spine. 2002;27:1652-8.

13. Iwasaki M, Okuda S, Miyauchi A, Sakaura H, Mukai Y, Yonenobu K, et al. Surgical strategy for cervical myelopathy due 
to ossification of the posterior longitudinal ligament: Part 2: Advantages of anterior decompression and fusion over laminoplasty. Spine. 2007;32:654-60.

14. Baba H, Imura S, Kawahara N, Nagata S, Tomita K. Osteoplastic laminoplasty for cervical myeloradiculopathy secondary to ossification of the posterior longitudinal ligament. Int Orthop. 1995;19:40-5.

15. Takano M, Komaki Y, Hikishima K, Konomi T, Fujiyoshi K, Tsuji $\mathrm{O}$, et al. In vivo tracing of neural tracts in tiptoe walking Yoshimura mice by diffusion tensor tractography. Spine. 2013;38: E66-72.

16. Kato Y, Kanchiku T, Imajo Y, Kimura K, Ichihara K, Kawano S, et al. Biomechanical study of the effect of degree of static compression of the spinal cord in ossification of the posterior longitudinal ligament. J Neurosurg Spine. 2010;12:301-5.

17. Maynard FM Jr, Bracken MB, Creasey G, Ditunno JF Jr, Donovan WH, Ducker TB, et al. International standards for neurological and functional classification of spinal cord injury. American spinal injury association. Spinal Cord. 1997;35:266-74

18. Granger CV, Albrecht GL, Hamilton BB. Outcome of comprehensive medical rehabilitation: measurement by PULSES profile and the Barthel Index. Arch Phys Med Rehabil. 1979;60:145-54.

19. Catz A, Itzkovich M, Agranov E, Ring H, Tamir A. SCIM-spinal cord independence measure: a new disability scale for patients with spinal cord lesions. Spinal Cord. 1997;35:850-6.

20. Catz A, Itzkovich M, Tamir A, Philo O, Steinberg F, Ring H, et al. SCIM-spinal cord independence measure (version II): sensitivity to functional changes. Harefuah. 2002;141:1025-31.

21. Itzkovich M, Gelernter I, Biering-Sorensen F, Weeks C, Laramee MT, Craven BC, et al. The Spinal Cord Independence Measure (SCIM) version III: reliability and validity in a multicenter international study. Disabil Rehabil. 2007;29:1926-33.

22. Saruhashi Y, Hukuda S, Katsuura A, Asajima S, Omura K. Clinical outcomes of cervical spinal cord injuries without radiographic evidence of trauma. Spinal Cord. 1998;36:567-73.

23. Shimomura T, Sumi M, Nishida K, Maeno K, Tadokoro K, Miyamoto $\mathrm{H}$, et al. Prognostic factors for deterioration of patients with cervical spondylotic myelopathy after nonsurgical treatment. Spine. 2007;32:2474-9.

24. Nakamura M, Fujiyoshi K, Tsuji O, Konomi T, Hosogane N, Watanabe $\mathrm{K}$, et al. Clinical significance of diffusion tensor tractography as a predictor of functional recovery after laminoplasty in patients with cervical compressive myelopathy. J Neurosurg Spine. 2012;17:147-52.

25. Iwasaki M, Okuda S, Miyauchi A, Sakaura H, Mukai Y, Yonenobu K, et al. Surgical strategy for cervical myelopathy due to ossification of the posterior longitudinal ligament: Part 1: clinical results and limitations of laminoplasty. Spine. 2007;32:647-53.

26. Ogawa Y, Toyama Y, Chiba K, Matsumoto M, Nakamura M, Takaishi $\mathrm{H}$, et al. Long-term results of expansive open-door laminoplasty for ossification of the posterior longitudinal ligament of the cervical spine. J Neurosurg Spine. 2004;1:168-74.
27. Chikuda H, Seichi A, Takeshita K, Matsunaga S, Watanabe M, Nakagawa $\mathrm{Y}$, et al. Acute cervical spinal cord injury complicated by preexisting ossification of the posterior longitudinal ligament: a multicenter study. Spine. 2011;36:1453-8.

28. Asazuma T, Satomi K, Suzuki N, Fujimura Y, Hirabayashi K. Management of patients with an incomplete cervical spinal cord injury. Spinal Cord. 1996;34:620-5.

29. La Rosa G, Conti A, Cardali S, Cacciola F, Tomasello F. Does early decompression improve neurological outcome of spinal cord injured patients? Appraisal of the literature using a meta-analytical approach. Spinal Cord. 2004;42:503-12.

30. Oichi T, Oshima Y, Okazaki R, Azuma S. Preexisting severe cervical spinal cord compression is a significant risk factor for severe paralysis development in patients with traumatic cervical spinal cord injury without bone injury: a retrospective cohort study. Eur Spine J. 2016;25:96-102.

31. Papadopoulos SM, Selden NR, Quint DJ, Patel N, Gillespie B, Grube S. Immediate spinal cord decompression for cervical spinal cord injury: feasibility and outcome. J Trauma. 2002; $52: 323-32$.

32. Schroeder GD, Kepler CK, Hjelm N, Vaccaro AR, Weinstein MS. The effect of vertebral fracture on the early neurologic recovery in patients with central cord syndrome. Eur Spine J. 2015;24:985-9.

33. Fehlings MG, Vaccaro A, Wilson JR, Singh A, Cadotte DW, Harrop JS, et al. Early versus delayed decompression for traumatic cervical spinal cord injury: results of the surgical timing in acute spinal cord injury study (STASCIS). PLoS ONE. 2012;7:e32037.

34. Chen L, Yang H, Yang T, Xu Y, Bao Z, Tang T. Effectiveness of surgical treatment for traumatic central cord syndrome. J Neurosurg Spine. 2009;10:3-8.

35. Anderson DG, Sayadipour A, Limthongkul W, Martin ND, Vaccaro A, Harrop JS. Traumatic central cord syndrome: neurologic recovery after surgical management. Am J Orthop. 2012;41: E104-8.

36. Aarabi B, Alexander M, Mirvis SE, Shanmuganathan K, Chesler D, Maulucci C, et al. Predictors of outcome in acute traumatic central cord syndrome due to spinal stenosis. J Neurosurg Spine. 2011;14:122-30.

37. Newton D, England M, Doll H, Gardner BP. The case for early treatment of dislocations of the cervical spine with cord involvement sustained playing rugby. J Bone Joint Surg Br. 2011;93:1646-52.

38. Guest J, Eleraky MA, Apostolides PJ, Dickman CA, Sonntag VK. Traumatic central cord syndrome: results of surgical management. J Neurosurg. 2002;97:25-32.

39. Takao T, Morishita Y, Okada S, Maeda T, Katoh F, Ueta T, et al. Clinical relationship between cervical spinal canal stenosis and traumatic cervical spinal cord injury without major fracture or dislocation. Eur Spine J. 2013;22:2228-31.

40. Suda K, Taneichi H, Kajino $T$, Otomo $H$, Moridaira $H$, Yamaguchi $\mathrm{M}$, et al. Risk factor analysis of tetraplegia after a minor trauma in patients with ossification of the posterior longitudinal ligament, the indication of prophylactic decompression for asymptomatic patients. Spine J. 2005;5:S78. 